\title{
CONCEPÇÕES DE POLIVALÊNCIA E PROFESSOR POLIVALENTE: UMA ANÁLISE HISTORICO-LEGAL ${ }^{1}$
}

\author{
Shirleide Pereira da Silva Cruz ${ }^{2}$ \\ Nathália Barros Ramos ${ }^{3}$ \\ Kátia Augusta Curado Pinheiro Cordeiro da Silva ${ }^{4}$
}

\section{Resumo}

As concepções de polivalência e professor polivalência são resultantes de um processo histórico relacionadas à visão de educação, escola, conhecimento e formação profissional. Assim, o texto descreve, a partir de alguns documentos oficiais educacionais, tal processo no período de 1970 até as reformas pós anos 1990. Percebe a noção de polivalência e professor polivalente associada a um sentido generalista e superficial de trato com os conteúdos curriculares denotando uma relação economicista de relação "custo-benefício" sob a justificativa de se suprir o déficit de professores para atuarem na crescente população escolar com ensino obrigatório estendido no período militar. Após as reformas dos anos 90 os documentos dão indícios de uma lógica das competências tanto como conteúdo formativo profissional como modo de construção do conhecimento por parte dos sujeitos. Tais documentos referendam ainda uma noção de conhecimento baseada numa perspectiva de interdisciplinaridade um tanto frágil quando esta é transposta do contexto epistemológico para o contexto educacional e pedagógico o que fragiliza também, uma compreensão apolítica de competências aos processos de profissionalização docente reforçando uma lógica de responsabilização.

Palavras-chave: Polivalência. Professor polivalente. Ensino fundamental.

\section{CONCEPTS OF VERSATILITY AND VERSATILE PROFESSOR: AN HISTORICAL-LEGAL ANALYSIS}

\begin{abstract}
The concepts of versatility and multi-skilling teacher is the result of a historical process related to the vision of education, school, knowledge and training. Thus, the text describes, based in a set of some educational official documents, this process from 1970 until after the 1990 reforms.Realize the notion of versatility and multi-purpose teacher associated with a general and superficial sense of dealing with curriculum content denoting economistic relation ratio "cost-benefit" on the grounds to meet the shortfall of teachers to work in the growing school population with compulsory education extended during the military period. After the reforms of the 90 the documents gives evidence the skills logic both as a professional training content as construction mode of knowledge of the subjects. In addition, endorses a notion of knowledge based on an interdisciplinary perspective somewhat fragile when it is transposed from the epistemological context for the educational and pedagogical context which weakens also an apolitical comprehension skills to teacher professionalization process strengthening accountability logic.
\end{abstract}


Keywords:Versatility. Polyvalent teacher. Primary school.

\section{INTRODUÇÃO}

O presente estudo tem como objetivo discutir a polivalência como princípio de formação e atuação do professor nos anos iniciais do ensino fundamental (AIEF). Tal discussão reconhece a polivalência como organização curricular escolar e como elemento configurador da profissionalidade do docente que atua nos AIEF da qual se depreende a denominação de professor polivalente. Reconhece-se ainda que esta denominação é resultante de um processo histórico no qual são definidas concepções sobre a educação, a escola, o conhecimento e a formação profissional. $\mathrm{Na}$ atualidade esta denominação de professor polivalente traz consigo uma série de representações que nem sempre estão associadas ao que se definiu sobre a polivalência como princípio de formação e atuação daquele profissional.

Nesse sentido, objetivamos realizar uma análise histórica de como a polivalência aparece na organização escolar tendo rebatimentos tanto para a formação como para o exercício profissional do docente dos AIEF. Assim, a regulamentação da polivalência tem figurado em diversos dispositivos da legislação educacional e, de forma diversa, em diferentes momentos históricos. Para tanto, descrevemos no conjunto de alguns documentos oficiais educacionais como esses termos - polivalência e professor polivalente - são apresentados e quais são as bases teóricas que os apoiam.

Em estudos de cunho histórico o estudo da legislação educacional ainda tem sido uma forma de se compreender em diálogos entre tempos e espaços diferenciados como ideias, discursos e proposições surgem, ganham força ideológica e podem perdurar ao longo do movimento histórico. De acordo com Faria Filho (1998, p. 92) um estudo que tem a legislação como corpus documental necessita considerar a lei "[...] como ordenamento jurídico, mas também como linguagem e prática social". Dessa forma, reconhecemos que a indicação da polivalência e a caracterização de professor polivalente passa pela compreensão de que esses conceitos integram as leis sendo estas configuradas com o ordenamento e a instituição de determinadas relações sociais as quais, por conseguinte, podem servir de inspiração de novas práticas mediante a apropriação e ação dos sujeitos. (FARIA FILHO, 1998).

Delimitamos o período para o estudo em questão alguns documentos produzidos partir do governo militar (1964-1980), outros dos anos 1990 e do período pós-reformas. Esta escolha deve-se ao fato de consideramos que é a partir do contexto socioeconômico de reorganização do capital, estruturada pós a década de 1960, cuja preocupação se voltou para os problemas de crescimento econômico e uma melhor distribuição de renda que vai ganhar força a teoria do capital humano. Tal teoria baseia-se no pressuposto de que existe uma relação direta entre o grau de educação possuído pelos indivíduos e a positividade dos seus rendimentos pessoais. E esta relação seria, então, resultado de decisões deliberadas de investimento em educação ou em treinamento, gerando-se, assim, o capital humano. É nesse mesmo contexto que dar-se-á ênfase na melhoria do nível de especialização dos 
trabalhadores e o aumento das habilitações e uma maior acumulação de conhecimento (sejam científicos, gerenciais, artísticos, etc.) reconhecidos como fatores importantíssimos para o crescimento econômico. (ALMEIDA; PEREIRA, 2012). Dessa teoria, portanto, derivam concepções de um perfil de professor para atender às demandas de formação que o novo papel da educação vai assumir neste período.

Já nos anos 1990 a reforma de Estado e seus desdobramentos nas reformas educativas empreendidas logo após, estes conceitos - o de polivalência e de professor polivalente parecem ser ressignificados a partir do processo de restruturação produtiva sob as bases do modelo toytista. Nessa reforma do Estado brasileiro, estarão subjacentes as ideias neoliberais formuladas, em âmbito internacional, para atenderem à reestruturação do capital frente a sua crise iniciada no final dos anos de 1970 e acentuada no final dos anos de 1980 por meio do desmonte do Estado de Bem-Estar Social. Assim, sob a égide de um discurso que atribuía a crise da educação a ineficiência da gestão, a má formação dos professores, os currículos inadequados e a falta de insumos, as reformas educativas desencadeadas no Brasil priorizaram cinco aspectos fundamentais: a gestão dos sistemas de ensino e da escola, o financiamento da educação escolar, o currículo, a formação e a avaliação.

Dessa forma, inserida nesse contexto, a formação de professores ganhou uma centralidade estratégica em tais reformas. Tal centralidade se expressa em dois principais aspectos: o fato de os professores serem responsabilizados pela crise da educação e, ao mesmo tempo, serem vistos como alternativa principal para as soluções dos problemas surgidos a partir dela. Segundo Batista Neto,

[...] a instituição dos Parâmetros curriculares Nacionais em 1995, a promulgação da nova Lei de Diretrizes e Bases, Lei 9394/96 e da Lei do FUNDEF (Fundo Nacional de Valorização do Ensino Fundamental), Lei 9424/96 e um sem números de decretos, resoluções, pareceres e instruções normativas que para regulamentar, no detalhe, dispositivos gerais das Leis mencionadas; balizaram a formação de professores no país, estabelecendo seus princípios, conceitos e suas diretrizes, bem como definiram os espaços institucionais para a formação de professores da Educação Básica. (2006, p. 58).

Empreendemos no estudo uma metodologia quantitativa e qualitativa que se desenvolveu inicialmente pelo levantamento dos documentos oficiais voltados para os períodos elegidos sendo estes separados e catalogados pela sua tipologia: i) Pareceres, ii) Decretos, iii) Leis, iv) Portarias e v) Resoluções. O acesso aos documentos se deu basicamente nos sítios institucionais do Ministério da Educação e do Conselho Nacional de Educação, este último hospedado naquele mesmo sítio e em alguns sítios de busca da internet. Após esse levantamento inicial, foi feita uma triagem dos documentos que faziam alguma referência ao professor das series iniciais, a partir das palavras-chave: polivalência, professor polivalente, professor multidisciplinar e professor dos anos iniciais.

A seguir apresentamos sob quais perspectivas a polivalência e o professor polivalente no contexto dos anos iniciais do ensino fundamental foram apontados.

\section{A NOÇÃO DE POLIVALÊNCIA NOS DOCUMENTOS EDUCACIONAIS DOS ANOS 1970}




\section{Revista HIIST'TEIDBR On-line}

O termo polivalência ou polivalente no período que compreende o governo militar foi apresentado pelo Conselho Federal de Educação, a partir das indicações do Conselheiro Valnir Chagas. Este conselheiro apresentou algumas indicações que tinham como foco a regulamentação da formação de professores naquele período. Uma boa parte de suas indicações não foi aprovada, mas, figuraram como elementos polêmicos para esse campo de formação profissional.

Dessa forma, na Indicação não promulgada do CFE de $n^{0} 23 / 73$, subsidiada por pareceres anteriores desse mesmo conselheiro, os de $\mathrm{n}^{\mathrm{o}} 252 / 69$ e de $\mathrm{n}^{\mathrm{o}} 283 / 69$, foi proposta a ideia de polivalência para afirmar um núcleo comum nos currículos a partir da compreensão de que o professor não é um "tarefeiro" e precisa vivenciar uma formação que lhe garanta compor junto ao processo educativo, a dimensão da preparação integral do aluno, dos conteúdos das matérias a serem ensinadas e dos métodos apropriados para atender a tais especificidades. Assim, aquela Indicação fomentou a implementação das licenciaturas curtas que além de refletirem um cerceamento ideológico, característico do governo militar, reduzindo o tempo de preparação intelectual e crítica num curso em nível superior, apresentou-se como uma solução aligeirada para se suprir a falta de professores habilitados para atuarem na docência no nível médio de ensino. A Indicação 23/73 do CFE instituiu as licenciaturas polivalentes de Educação Artística e Ciências regulamentadas pela Resolução n ${ }^{\circ}$ 23/73, para Educação Artística e Resolução n 30/74 para Ciências.

Já em 1964, essa Indicação havia sido feita pelo Conselheiro Newton Sucupira quando da implantação de licenciaturas, em caráter especial, visando formar professores para o antigo curso ginasial, nas áreas de Letras, Estudos Sociais e Ciências, proposição que foi retomada, anos depois, por Valnir Chagas. Assiste-se, assim, a um esfacelamento da formação docente tanto para o ensino dos anos iniciais de escolarização como para os estudos em nível médio, na medida em que foi permitida e organizada uma base superficial de conteúdos de formação, um aligeiramento e um condensamento das disciplinas escolares em áreas curriculares com pouca definição de seus objetos de estudo.

Data desse período, por exemplo, o que aconteceu com a História como disciplina curricular. Esta sofrerá uma significativa mudança quando da implementação da Lei $\mathrm{n}^{\circ}$ 5692/71 que ao dar destaque aos conteúdos técnicos de cunho prático, utilitário e experimental, diminuiu a formação geral do aluno construída por meio dos conhecimentos sobre o meio social, econômico, político e cultural, substituindo e descaracterizando o ensino de História, juntamente, com o de Geografia, pela área de Estudos Sociais. Essa perspectiva curricular de ensino terá, portanto, rebatimento para a formação docente nessa área de Estudos Sociais. Nesse sentido, o Parecer $n^{\circ}$ 895/71 retoma a ideia de polivalência através da indicação de que o professor polivalente seria aquele que atua do $1^{\circ}$ ao $2^{\circ}$ graus, podendo ministrar disciplinas diferentes, embasando, dessa forma, a ideia de formação de professores generalistas.

Essas posições parecem ter sido reforçadas pela aprovação do Parecer $n^{\circ} 349 / 72$, que recomendava a habilitação específica de magistério em duas modalidades: uma com duração de três anos que habilitaria a lecionar até a $4^{a}$ série e outra com a duração de quatro anos que habilitaria para o magistério até a $6^{\mathrm{a}}$ série do $1^{\circ}$ grau. De forma mais geral, a Lei ${ }^{\circ}$ 5692/71 teve outro impacto sobre o currículo da HEM ao formular uma outra proposição curricular, segundo a qual o ensino de $1^{\circ}$ grau seria organizado por atividades, o que pressupunha 
também um outro tipo de formação dos professores das séries iniciais. O termo "atividade" foi mais explicitado pelo Parecer $n^{\circ} 853$, de 12 de novembro de 1971, e pela Resolução $n^{\circ} 8$ de $1^{\circ}$ de dezembro do mesmo ano, ambos do Conselho Federal de Educação. Segundo Castellani Filho (1988), a atividade parecia ganhar um caráter de "[...] fazer prático não significativo de uma reflexão teórica [...]”. Considerava-se, então, como experiências que necessariamente não assumiam um caráter formal no currículo da escola". (CASTELLANI FILHO, 1988, p. 6). Naquele mesmo parecer, o Conselho Federal de Educação indica como as matérias de ensino deveriam apresentar-se "didaticamente assimilável", sob três diferentes formas: em atividades, áreas de estudo e disciplinas, aspecto esse que parece ser referendar a observação de Castellani Filho anteriormente apontada.

Mimesse (2007) resume como esse processo deveria ser desencadeado a partir da orientação daquele documento norteador: Nas atividades, a aprendizagem deveriam ocorrer a partir de experiências concretas; já nas áreas de estudo, as situações concretas seriam equilibradas com os conhecimentos sistemáticos, além de se efetuar a integração de conteúdos afins. Nas disciplinas, a aprendizagem deveria se desenvolver por meio do conhecimento sistemático. (MIMESSE, 2007, p. 107). Há, portanto, uma indicação implícita de que o nível de ensino em que, predominantemente, há o atendimento realizado às crianças poderia efetivar o estudo das matérias através de atividades, para assim se adequar às necessidades e possibilidades concretas de desenvolvimento dos alunos. Essa indicação legal parece retomar uma visão restrita e pragmática do ensino nos anos iniciais de escolarização e denotar a não necessidade de o professor desenvolver um aprofundamento teórico sistematizado, cabendo essa característica apenas para o "professor de disciplina" ou "professor de matéria".

Essa prescrição curricular parece refletir também a influência da abordagem tecnicista e das teorias comportamentalistas de aprendizagem no ensino na educação brasileira dos anos de 1970. Tal abordagem baseia-se no modelo de professor aplicador de técnicas e executor de manuais, desenvolvendo ainda o controle da aprendizagem. As atividades, provavelmente, não seriam autonomamente planejadas pelos professores nesse contexto. Esse aspecto, segundo Sarmento, pode ser considerado também como um dispositivo de desqualificação docente, caracterizada “[...] pela intromissão de procedimentos de controlo técnico, pela sofisticação dos processos de gestão e pela normatização e standartização dos processos pedagógicos de ensino e avaliação, designadamente com currículos de base condutista". (1994, p. 40).

Somada a essas mudanças declarou-se a obrigatoriedade do ensino de Educação Moral e Cívica, da Educação Física, de Educação Artística e de Programas de Saúde nos currículos plenos dos estabelecimentos de $1^{\circ}$ e $2^{\circ}$ graus, ampliando-se as demandas para a docência do professor das séries iniciais daquele período, expressando um "alargamento" da polivalência. Contudo, os dispositivos legais não apontavam claramente como esta deveria se efetivar no seio das escolas e das salas de aula.

No Parecer CFE $n^{\circ}$ 540/77, relativo à prática pedagógica, por exemplo, aponta-se que a "Educação Artística não se dirigirá, pois, a um determinado terreno estético. ", sendo esta ministrada, preferencialmente polivalente no $1^{\circ}$ grau". (BRASIL, 1979, p. 196-197, apud PENNA, 2010, p. 51). 
Infere-se, diante do exposto até o momento, que a noção de polivalência estaria associada a um sentido generalista e superficial de trato com os conteúdos curriculares denotando uma relação economicista de relação "custo-benefício" sob a justificativa de se suprir o déficit de professores para atuarem na crescente população escolar com ensino obrigatório estendido no período para oito anos. Já a noção de professor polivalente seria associada à visão de que este seria um profissional que transita por diferentes áreas de conhecimentos articulando saberes e procedimentos.

\section{APONTAMENTOS E SILENCIAMENTOS NOS ANOS 1980 E O MOVIMENTO DAS REFORMAS EDUCATIVAS DOS ANOS 1990}

Nos anos de 1980, ainda sob forte interferência da teoria do capital humano influenciando as concepções sobre a educação internacional e nacional, o termo polivalência não romperá com a visão tecnicista de formação profissional, justificada pela proposição de seria importante uma base generalista sob a qual se garantiria níveis altos de especialização, separando-se, assim, concepção e execução. Ressalta-se, porém, que no campo específico da formação de professores observa-se certo silêncio na legislação sobre a temática da polivalência, contudo, no campo científico apareceriam discussões sobre esse conceito atrelado à noção de politecnia. Nesse contexto, desenvolve-se um movimento que se caracteriza pela crítica ao "trabalhador polivalente" e sua formação, com base na ideia do "trabalhador politécnico". O trabalhador polivalente seria aquele apto a realizar diferentes tarefas, a crítica a esse perfil de trabalhador se dá pela concepção de que os indivíduos não devem apenas ser tarefeiros ou multitarefeiros, mas sim ser um trabalhador politécnico capaz de compreender os fundamentos científicos das diferentes técnicas que caracterizam o processo de trabalho produtivo atual de modo a não separar trabalho manual do trabalho intelectual. O foco, então, não é na tarefa, mas, nas possibilidades de formação que uniriam formação profissional e formação geral. (SAVIANI, 1989). Esse movimento inspira-se em correntes marxistas e tem gerado debates e propostas no campo educacional, orientando o ensino para um posicionamento crítico às atividades produtivas baseadas nos fundamentos da ciência 5 .

Assim, no geral, o termo "polivalência" tem sido comumente usado no contexto do mundo do trabalho, requisitado pelo discurso neoliberal no período pós-crise do capitalismo. Designa a capacidade de o trabalhador poder atuar em diversas áreas, podendo caracterizar ainda um profissional pautado pela flexibilização funcional. Esse entendimento da polivalência tem, por vezes, exercido certa influência na visão que se faz do professor dos anos iniciais quando há referência de que ele tem a cumprir múltiplas funções, aproximandose de uma visão de profissional de competência multifuncional.

Contudo, o termo polivalente permaneceria nas conversações cotidianas e em algumas indicações de trabalhos que analisavam o professor que atua nos anos iniciais do Ensino Fundamental. Na versão preliminar de 1998 dos Referenciais Curriculares para a Formação de Professores, utiliza-se o termo polivalente toda vez que se faz referência ao profissional que atua nos anos iniciais do Ensino Fundamental. Já a versão final de 2002 fixou a denominação de professor multidisciplinar. Essa denominação também foi utilizada nos censos de professores elaborados pelo Instituto de Pesquisas Anísio Teixeira, Inep. 


\section{Revista HIIST'TEIDBR On-line}

Segundo estudo exploratório realizado pelo Instituto Nacional de Estudos e Pesquisas Educacionais Anísio Teixeira (Inep), com base no Censo de 2007, esse professor leciona cinco ou mais disciplinas. Recebe ainda, nesse mesmo documento, a denominação de "Professor unidocente", de onde a designação de professor multidisciplinar é caracterizada como aquele profissional que trabalha em todos os campos do conhecimento ministrados nas várias disciplinas do currículo escolar.

A indicação de professor multidisciplinar apontada pelo documento do Inep parece indicar um caráter mais quantitativo da definição da profissionalidade polivalente, o que não é referendado nos referenciais, uma vez que a perspectiva multidisciplinar se direcionaria para uma diversidade de disciplinas com ênfase na articulação. Aquele caráter quantitativo, de certa maneira, está consensuado para os docentes que têm a habilitação profissional com a demanda de lecionar diversas disciplinas, ou seja, para o professor dos anos iniciais do Ensino fundamental. Por seu turno, Brzezinski (2008) discute a denominação de professor multidisciplinar com um caráter mais qualitativo, referindo-se ao domínio de um conhecimento peculiar para o atendimento dos alunos dos AIEF por meio de uma prática unodocente que confere uma identidade própria, sendo ademais necessário que sua formação privilegie o desenvolvimento de uma postura científica, ética, política, didática e técnica. Essa perspectiva parece ainda se coadunar com a definição de polivalência posta pelo Parecer CNE/CEB n'16/99, segundo o qual a polivalência seria: "[...] o atributo de um profissional possuidor de competências que lhe permitam superar os limites de uma ocupação ou campo circunscrito de trabalho para transitar para outros campos ou ocupações da mesma área profissional ou de áreas afins”. (BRASIL, 1999c, p. 37).

No Parecer CNE n 5/1997 quando se refere à metodologia recomendável em sala de aula ressalta que esta deve ser feita por professora única polivalente. Nesse sentido seriam polivalentes os professores dos anos iniciais que dominassem diferentes áreas de conhecimento que compõe o currículo dos anos iniciais, sendo que é destinado apenas um professor por turma. Como o documento não deixa clara a justificativa do motivo de ser ter apenas um único professor problematizamos que o sentido de polivalente estaria mais associado à noção de trabalhador polivalente ressignificada pela restruturação produtiva do capital no final dos anos 1980 e acentuada nas reformas de estado dos anos 1990 do que à uma explicação mais pedagógica dessa indicação.

O Decreto Presidencial n ${ }^{\circ} 3.276$, de 6/12/99, no Art. $3^{\circ}$, parágrafo $2^{\circ}$, ressalta que "[...] a formação em nível superior de professores para atuação multidisciplinar, destinada ao magistério na Educação Infantil e nos anos iniciais do Ensino Fundamental, far-se-á exclusivamente em cursos normais superiores". (BRASIL, 1999a). Esse decreto causou uma polêmica em relação à formação de professores para os anos iniciais de escolarização no país, pois desconsiderou a experiência histórica acumulada pelos cursos de pedagogia que habilitavam esse profissional e por, de certa maneira, atribuir grande importância a uma instituição ainda inexistente. Por pressão social o Decreto é substituído pelo Decreto $\mathrm{n}^{\circ}$ 3.554, de 7 de agosto de 2000 que dá nova redação trocando o termo "exclusivamente" pelo "preferencialmente". Mais tarde, os próprios institutos perdem sua razão de ser com a promulgação das Diretrizes Curriculares para os cursos de pedagogia que em seu art. $4^{\circ}$ definia o "magistério na Educação Infantil e nos anos iniciais do Ensino Fundamental, nos cursos de Ensino Médio, na modalidade Normal, de Educação Profissional na área de 
Artigo

doi: $10.20396 /$ rho.v17i2.8645863

serviços e apoio escolar e em outras áreas nas quais sejam previstos conhecimentos pedagógicos" como habilitação para os formados pelo referido curso.

É mister ressaltar que os sistemas de ensino recebem uma grande influência do sistema econômico, trazendo assim uma desqualificação e atomização de tarefas no âmbito da produção de trabalho que também foi reproduzido no interior dos sistemas educacionais. Nesse sentido "[...] a flexibilidade e polivalência da classe trabalhadora possibilita que uma mesma pessoa seja responsável pelo manejo e controle de várias máquinas, ao contrário do modelo fordista no qual devia atender apenas a uma tarefa". (SANTOMÉ, 1998). Com isso percebemos que os discursos oficiais e as reformas educacionais se baseiam em ideias e interesses gerados por esferas da vida econômica e social. Esse discurso, denominado de neoliberal por muitos estudiosos, do trabalhador polivalente, propaga essa visão como um atributo contemporâneo deste trabalhador, que se adapta a contextos diversos e que é possuidor de várias competências que lhe permitem atuar em diversas áreas de trabalho aumentando a produtividade aliada à eficiência, sendo ainda caracterizado como um profissional que apresenta uma flexibilização funcional.

Um outro aspecto a destacar encontrado no Parecer CNE n 5/1997 foi a questão de gênero. Observou-se que a menção feita nele foi a de que a metodologia recomendável em sala de aula deve ser feita por professora única polivalente, restringindo assim ao gênero feminino como profissional para atuar nessa etapa de ensino nos AIEF. Esse aspecto parece ser apresentado no referido documento de forma naturalizada e nos faz refletir que a profissionalidade para atuar nestes anos pode ficar fragilizada por uma visão sexista e, já de pronto, distanciar os jovens do sexo masculino que desejem atuar nessa área profissional.

Aquela linha de pensamento da polivalência como formação e atuação do trabalhador multifuncional parece permanecer no Parecer CNE/CEB nº $16 / 99$, neste a polivalência explicitaria o "[...] desenvolvimento das competências gerais, apoiadas em bases científicas e tecnológicas e em atributos humanos, tais como criatividade, autonomia intelectual, pensamento crítico, iniciativa e capacidade para monitorar desempenhos". (BRASIL, 1999c, p. 37). No contexto atual do mundo do trabalho, dado o avanço das tecnologias propiciado inicialmente pela microeletrônica e a eletromecânica, observa-se, de um lado, a defesa entusiasmada da "polivalência", entendida como atributo do trabalhador contemporâneo, adaptado a contextos diversos e possuidor de competências múltiplas que lhe permitem atuar em diferentes postos de trabalho, agregando eficiência e aumento da produtividade. Mesmo parecendo ampliar a formação dos indivíduos a polivalência não romperia com a divisão entre trabalho manual e trabalho intelectual pois a lógica da eficiência não garantiria um efetivo processo de formação em termos de tempo e de fundamentos, ou seja, reforçaria a ideia de formar mais sujeitos com menos custos e, por sua vez, ter menos sujeitos realizando mais tarefas.

\section{AOS ANOS 2000 E A VISÃO RESSIGINIFICADA DE PROFESSOR POLIVALENTE}

Na Resolução CNE/CP n ${ }^{\circ} 1$ de 30 de novembro de 1999 e no Decreto n $45.348 / 2000$ é indicada a organização curricular dos cursos destinados à formação de professores para o 


\section{Revista HIISTEYIDIR On-line}

ensino fundamental e regulamentada a atuação profissional. No Decreto $\mathrm{n}^{\circ} 45.348 / 2000$, no Artigo $3^{\circ}$ indica-se que a definição do profissional do magistério, abrange a docência polivalente ou exclusiva de componentes curriculares. Já a Resolução CNE/CP nº 1/1999 ressalta que os cursos de licenciatura destinados à docência serão organizados em habilitações polivalentes ou especializadas por disciplina ou ainda por área de conhecimento. Diante do exposto, depreende-se que a lógica das habilitações polivalentes já existente desde os anos 1970 instituída pela Indicação 23/73 do Conselho Federal de Educação e regulamentada pelas Resoluções $n^{\circ}$ 23/73 e n $n^{\circ} 30 / 74$, permanecia nas indicações legais ainda no final dos anos 1999 e esta só viria a ser modificada após a elaboração dos Referenciais Nacionais para formação dos profissionais da educação Básica, documento elaborado apenas no ano de 2002, bem como com a própria LDB 9394/96 anteriormente promulgada com a qual não parecia dialogar. Esse aspecto reflete ainda o próprio movimento de modificações empreendidos nos sistemas de ensino para atender à demanda de professores para atuar no contexto da universalização do ensino fundamental desencadeada após os acordos internacionais assinados nos anos 1990.

Com a palavra-chave, professor dos anos iniciais, identificamos a referência dos Pareceres CNE nº 115/99 e 970/99 que vão tratar da formação de professores para esses anos iniciais, apontando que se tem exigido progressivamente o diploma de nível superior nos concursos públicos para professores do AIEF. E com a elevação da formação inicial dos professores dos AIEF em nível superior pela LDB n ${ }^{\circ}$ 9394/96 se tem constituído um aspecto importante no processo de profissionalização docente da educação básica, sendo essa forma de acesso por meio de concurso público requerendo a elevação da formação em nível superior uma medida para a valorização da profissão. Assim, a Constituição Federal de 1988 afirma a valorização aos profissionais do ensino, trazendo assim uma dimensão profissional da docência. A aprovação em concurso, por sua vez, vai ser um dos elementos determinantes para a constituição da identidade profissional dos professores por proporcionar estabilidade e permanência no cargo. Contudo, a despeito da busca pela elevação da formação docente para os AIEF permanece como exigência mínima a formação em nível médio na modalidade normal, o que se apresenta ainda como uma contradição na construção da profissionalidade docente polivalente.

Mais adiante no Parecer CNE n 11/2000 que versa sobre as Diretrizes Curriculares Nacionais para a Educação de Jovens e Adultos identificamos a referência à formação docente para essa modalidade de ensino com uma qualificação multidisciplinar e polivalente. Vê-se aqui que esses dois termos parecem se diferenciar entre si nesse documento. Assim, polivalente indicaria a presença de um único professor por turma, conforme já mencionamos a partir do Parecer CNE nº 5/1997. Já multidisciplinar se referiria ao número de disciplinas com as quais deveria atuar.

No Parecer CNE/CP n ${ }^{\circ}$ 9/2001 que versa sobre Diretrizes Curriculares Nacionais para a Formação de Professores da Educação Básica, em nível superior, curso de licenciatura, de graduação plena, empreende-se uma discussão destacando-se que cursos de formação de professores para atuação multidisciplinar, na maioria das vezes, tratam superficialmente ou praticamente não tratam os conhecimentos sobre os objetos de ensino com os quais irão trabalhar. Em contrapartida os cursos das licenciaturas em áreas específicas do conhecimento supervalorizam os conteúdos a serem ensinados. Os relatores 


\section{Revista HIISTEYIDIR On-line}

ainda fazem a ressalva de que a definição de que um professor de atuação multidisciplinar precisa saber sobre as diferentes áreas de conhecimento não é tarefa simples. Neste documento pondera-se que aquele professor precisa conhecer e dominar os conteúdos básicos relacionados às áreas de conhecimento que serão objeto de sua atividade docente. Contudo, não é que ele tenha um conhecimento tão estrito, basicamente igual ao que vai ensinar, como também não se pretende que se tenha um conhecimento tão aprofundado e amplo como o do especialista por área de conhecimento. (BRASIL, 2001, p. 38-39).

É válido ressaltar que no CNE/CP n 9/2001 a referência a professor multidisciplinar não se restringe ao professor dos anos iniciais do ensino fundamental, mas, também a professores em algumas áreas de conhecimento do ensino fundamental, neste caso, referindo-se aos anos finais, tais como Ciências Naturais ou Artes, que "[...] pressupõem uma abordagem equilibrada e articulada de diferentes disciplinas". (BRASIL, 2001, p. 27). Biologia, Física, por exemplo, no caso das Ciências Naturais e diferentes linguagens tais como, da Música, da Dança, das Artes Visuais, para o caso de Artes.

O parecer CNE/CP n ${ }^{\circ}$ 9/2001 referenda a Resolução CNE/CP 1, de 18 de fevereiro de 2002 e esta apenas indica no seu artigo $7^{\circ}$, inciso VIII que nas instituições de ensino superior não detentoras de autonomia universitária os Institutos Superiores de Educação seriam responsáveis por congregar os cursos de formação de professores que ofereçam licenciaturas em curso Normal Superior para docência multidisciplinar na educação infantil e anos iniciais do ensino fundamental ou licenciaturas para docência nas etapas subsequentes da educação básica. Sendo assim, apresentou-se como a única referência a "professor multidisciplinar" encontrada neste documento. Reflete-se nesse sentido, que a questão da atuação multidisciplinar para os AIEF foi tratada de forma similar a outras e não se aprofundou a especificidade da polivalência, ou seja, um único professor ministrando diferentes áreas de conhecimentos.

Após um outro período de silenciamento localizou-se o Parecer CNE/CEB nº/2008b que trata da orientação sobre os três anos iniciais do Ensino Fundamental de nove anos, a ressalva que os professores dos três (3) anos iniciais devem trabalhar de forma inter e multidisciplinar. Destaca-se neste mesmo ano a matéria encontrada e relatada pela conselheira Regina Vinhaes Gracindo no Parecer $n^{\circ}$ 2/2008a, sobre a relação entre formação e atuação docente em resposta a questionamentos feitos pela Secretaria de Educação do município de Contagem-MG. Os questionamentos feitos foram: Considerando a lógica dos ciclos de formação e a concepção de profissionais de Educação Básica prevista na LDB e nas Diretrizes Curriculares para a formação de docentes, elaboradas por esse egrégio Conselho, solicitamos parecer quanto: 1 . à pertinência da atuação, no $3^{\circ}$ ano do $2^{\circ} \mathrm{Ciclo}$, de professores com formação em Curso Normal Superior e de Pedagogia com ênfase na Educação Infantil e nos anos iniciais do Ensino Fundamental; 2. à docência nos anos iniciais do Ensino Fundamental, ou seja, nos $1^{\circ}$ e $2^{\circ}$ Ciclos, por professores detentores de licenciatura com habilitações em áreas específicas. Em nosso caso, prevemos a atuação de professores de artes, inglês e educação física; 3. à atuação multidisciplinar, englobando áreas do conhecimento, de profissionais habilitados em disciplinas específicas. (BRASIL, 2008 p. 8).

Baseando-se em diversos decretos a relatora assim resume o seu voto no parecer: (i) os professores com formação em Curso Normal Superior e em Pedagogia, dada sua formação, devem atuar de forma multidisciplinar na Educação Infantil e nos anos iniciais do 
Ensino Fundamental, o que não atinge o $3^{\circ}$ ano do $2^{\circ}$ Ciclo; (ii) os licenciados em Artes Plásticas, Artes Cênicas, Educação Musical, Língua Estrangeira e Educação Física, por força da forma inter-relacionada com que esses conteúdos se apresentam, podem atuar em quaisquer dos ciclos de aprendizagem do Ensino Fundamental, com o cuidado de desenvolvê-los de forma não fragmentada e integrados à forma multidisciplinar, no caso dos anos iniciais do Ensino Fundamental; (iii) enquanto não houver uma radical mudança na forma específica e disciplinar da maior parte dos 14 cursos de licenciatura e tendo em vista a impossibilidade do docente atuar "[...] no ensino da sua especialidade", posto que inexistente na atuação multidisciplinar, os docentes oriundos das licenciaturas específicas devem atuar nos campos específicos curriculares, desta forma organizados nas séries finais do Ensino Fundamental e do Ensino Médio. (BRASIL, 2008a, p. 8).

Sua análise destacaria ainda que é importante “[...] não se confundir a atuação multidisciplinar com a formação multidisciplinar que está frequentemente indicada nas normas educacionais". (BRASIL, 2008a p. 8). Essa confusão, por vezes, vem fragilizado a profissionalidade docente para os anos iniciais uma vez que tende naturalizar uma relação direta entre formação e atuação que nem sempre é praticada na realidade educacional no seio das salas de aulas dos AIEF. No Decreto 3.276/1999, já discutido por nós também apresenta o termo multidisciplinar com três referências em relação tanto à formação e atuação docente.

Santomé (1998), apresenta algumas formas de diálogos entre diferentes áreas curriculares. Para ele a multidisciplinaridade seria a mera justaposição de matérias diferentes, oferecidas de maneira simultânea, tendo a intenção de esclarecer seus elementos comuns, mas não explicitando claramente as possíveis relações entre elas. Aquele autor se refere a Jean Piaget para indicar que a multidisciplinariedade apresenta um nível inferior de integração que ocorre para solucionar um problema, buscando assim informações e ajuda em várias disciplinas, sem que necessariamente essa interação contribua para modificá-las ou enriquecê-las. Já a pluridisciplinaridade seria uma justaposição de disciplinas próximas em uma mesma área de conhecimento visando, através da cooperação, uma melhor relação entre essas disciplinas. "Vem ser uma relação de mera troca de informações, uma simples acumulação de conhecimentos". (SANTOMÉ, 1998, p. 71). Ainda para o mesmo autor “[...] a interdisciplinaridade implica em uma vontade e compromisso de elaborar um contexto mais geral, no qual cada uma das disciplinas em contato é, por sua vez, modificada e passa a depender claramente umas das outras". (1998, p. 73). Dessa análise de Santomé (1998) depreende-se que a indicação do termo multidisciplinar, além de ser o termo que mais apareceu em toda a análise efetivada, apresentou um sentido quantitativo já destacado neste texto.

\section{UMA DÉCADA DAS DIRETRIZES CURRICULARES DO CURSO DE PEDAGOGIA DE 2006: O QUE APONTAM PARA O PROFESSOR POLIVALENTE?}

Com a promulgação das Diretrizes Curriculares do curso de Pedagogia em 2006, Resolução CNE $n^{\circ}$ 01/2006, retoma-se o debate sobre o papel do curso de Pedagogia na formação dos professores dos anos iniciais do Ensino Fundamental, justamente porque as Diretrizes destacam a função que esse curso deve assumir quanto à formação daqueles 


\section{Revista HIISTEYIDIR On-line}

Artigo

doi: 10.20396/rho.v17i2.8645863

profissionais. Têm-se, assim, definido o curso que vai assumir a formação desses professores em nível superior, sendo isso explícito no Art. $4^{\circ}$ : que o curso de Licenciatura em Pedagogia destina-se à formação de professores para exercer funções de magistério na Educação Infantil e nos anos iniciais do Ensino Fundamental [...].

Nessa mesma linha, as referidas Diretrizes consideram que a docência contempla tanto o trabalho desenvolvido em sala de aula como a gestão, incluído também o apoio técnico-pedagógico para os institutos tecnológicos de formação profissional. Promovem, dessa forma, uma espécie de "inchaço" nos currículos que, provavelmente, dificultará uma formação adequada para os futuros docente se possíveis interpretações para o sentido da polivalência e do professor polivalente.

Para dar conta dessa abrangência, as diretrizes enfatizam o desenvolvimento de uma formação interdisciplinar, cujo entendimento não é aprofundado em seu texto. O Art. $5^{\circ}$ da Resolução CNE 01/2006 (DCNP) orienta ainda que os professores tenham um conhecimento aprofundado de cada disciplina, de modo a identificar possibilidades de diálogo entre os vários saberes. Lima (2007), por sua parte, considera que o professor polivalente seria um sujeito capaz de apropriar-se de conhecimentos básicos das diferentes áreas do conhecimento, que compõem atualmente a base comum do currículo nacional dos anos iniciais do Ensino Fundamental, e de articulá-los. Dessa forma, desenvolver-se-ia um trabalho interdisciplinar. Para essa pesquisadora, a polivalência estaria associada a uma atuação interdisciplinar. Em relação a essa questão, Gatti e Nunes (2008) realizou uma pesquisa que teve como objetivo analisar os currículos prescritos para a formação de professores nos cursos de licenciatura, dentre eles os da licenciatura em Pedagogia. $O$ estudo constatou ser necessário ampliar a reflexão sobre a suficiência ou adequação das perspectivas polivalente e interdisciplinar em tais cursos, uma vez que se verificou superficialidade no trato dos conteúdos das diversas áreas do conhecimento (Português, Matemática, Artes, História, Geografia, entre outros) que compõem os currículos da educação básica. Do total de disciplinas obrigatórias e, de acordo com uma categoria de análise definida na pesquisa que dizia respeito aos "Conhecimentos relativos à formação específica", apenas 7,5\% dessas disciplinas são destinadas aos conteúdos a serem ensinados nas séries/anos iniciais do Ensino Fundamental, quando não aparecem apenas diluídos nas disciplinas referentes às metodologias (Metodologia do Ensino de Língua Portuguesa, Metodologia do Ensino da História). A pesquisadora concluiu que os conteúdos específicos das disciplinas a serem ministradas não são objetos dos cursos de formação e questionou se essa formação panorâmica para um profissional que irá planejar, ministrar aulas e avaliar o ensino das diversas áreas do conhecimento será capaz de dotá-lo de competências que o permita adotar uma prática interdisciplinar. Como ser capaz de desenvolver práticas interdisciplinares, tendo uma frágil base disciplinar? Eis a pergunta que se coloca. Para Gatti e Nunes (2008) a perspectiva interdisciplinar é complexa e requer um aprofundamento disciplinar lógico-conceitual para a constituição das condições do diálogo. Trata- se de algo difícil, segundo essa autora, de se obter, dada a forma como se apresentam os currículos dos cursos de Pedagogia.

A proposição da interdisciplinaridade como princípio da formação dos professores dos anos iniciais aparece também em outros textos oficiais. Dias (2009) afirma que ela é apontada tanto nas DCNP como nas Diretrizes Curriculares para a Formação de Professores 
da Educação Básica (DFPEB). É matéria, inclusive, de consenso entre várias comunidades epistêmicas de representação do professorado, tornando-se, assim, uma ideia hegemonizada nos ciclos de políticas para a formação de professores dos AIEF no período investigado por Dias (2009), que compreendeu os anos de 1996 a 2006. Parece, então, que a noção de polivalência estar endossada por uma perspectiva interdisciplinar de formação e atuação. Vê-se que as diretrizes ao indicar a perspectiva da interdisciplinaridade na formação do professor dos AIEF, contudo, não esclarece sob quais fundamentos e características esse princípio deve se apresentar e nortear os cursos de formação.

Nesse mesmo contexto das reformas, também foram implementados sistemas de avaliação nacionais e estaduais, expressando ainda mais o caráter regulador sob o qual o Estado brasileiro constituir-se-ia na direção de sua reforma. Data, então, desse período a implementação do Sistema de Avaliação da Educação Básica (SAEB), criado em 1992. Compõe este sistema a Avaliação Nacional da Educação Básica - Aneb (Saeb), que avalia os alunos de forma amostral, das $4^{\mathrm{a}}$ e $8^{\mathrm{a}}$ séries $\left(5^{\circ}\right.$ e $9^{\circ}$ anos) do Ensino Fundamental, em Língua Portuguesa (leitura) e Matemática (resolução de problemas), das redes pública e privada, nas áreas urbana e rural. Está incluída, no oitavo ciclo do SAEB, a Avaliação Nacional do Rendimento Escolar - Anresc (Prova Brasil), que avalia, a cada dois anos, em caráter censitário, todos os estudantes das escolas públicas da $4^{\mathrm{a}}$ e da $8^{\mathrm{a}}$ série $\left(5^{\circ} \mathrm{e} 9^{\circ}\right.$ anos $)$ do Ensino Fundamental, em Língua Portuguesa (leitura) e Matemática (resolução de problemas). No bojo desse quadro avaliativo, está uma estreita relação entre uma noção de competência e sua correspondência com um sistema de certificação. Assim, não foi por acaso que a lógica das competências permeia todos os demais documentos orientadores da formação inicial dos professores e dos currículos das escolas, tal como nos adverte Ramos (2001). A concepção de competência alinhava-se também às lógicas de formação humana e à educação correspondente a ser promovida, desencadeadas no pós-fordismo, no qual se deveria formar indivíduos multifuncionais, flexíveis, polivalentes, garantindo- se, assim, os mais altos níveis de empregabilidade possíveis.

Na Resolução n ${ }^{\circ}$ 07/2010 são indicadas diferentes formas de integração do currículo, no qual são sugeridos projetos de interdisciplinaridade com temas geradores formulados a partir de problemas da realidade; articulação de temas das áreas de conhecimentos a esses temas; o currículo em rede; a integração por conceitos-chaves ou conceitos-nucleares e questões culturais numa perspectiva transversal. Nesse mesmo documento, busca-se afirmar que com essa indicação não se pretende banalizar os conteúdos curriculares para os segmentos das camadas populares. (BRASIL, 2010, p. 21). Referenciadas pela perspectiva de Young (2007), essas orientações buscam destacar que tal articulação/integração curricular não pode prescindir de um estudo adequado dos conteúdos que só a escola, como instituição social transmissora do conhecimento acumulado da humanidade, diferentemente da família dos sujeitos, poderia assim o fazer, garantindo-se, assim, a não superficialidade ou esvaziamento teórico dos estudos dos conteúdos com uma contextualização que não avançasse para além dos saberes que os alunos já possuíam. Dessa forma, as diretrizes de 2010 também referenda a interdisciplinaridade para a atuação do professor polivalente.

Essa resolução indicou ainda que o trabalho nos anos iniciais do ensino fundamental necessita refletir sobre o tempo como um fator relevante para a efetivação da polivalência. Isso por que é esta resolução que também que vai nortear a instituição dos ciclos de 


\section{Revista HIIST'TEIDBR On-line}

Artigo

doi: $10.20396 /$ rho.v17i2.8645863

aprendizagem já orientados na lei do ensino fundamental de nove anos e para a instituição do bloco inicial de alfabetização. Reflete, então, sobre o contato temporal de um tempo maior empreendido na relação professor professor-aluno na organização pedagógica dos AIEF. Esse contato temporal e as demandas dele decorrentes apresentam-se nesse documento como um princípio cujo objetivo seria garantir tanto a continuidade e o diálogo entre o trabalho escolar nos anos iniciais e os anos finais do Ensino Fundamental como atenuar as modificações no Ensino Fundamental resultantes da passagem do professor dito de referência de turma -professor polivalente - (anos iniciais) para os professores de matéria (anos finais). Porém, tal proposição é indicada de forma muito superficial nesse documento sem um maior aprofundamento.

Promulgadas em junho de 2015, as Diretrizes Curriculares Nacionais para a Formação Inicial e Continuada dos Profissionais do Magistério da Educação Básica, Resolução CNE/CP n ${ }^{\circ}$ 02/2015, não faz referência aos termos polivalente ou polivalência e dá destaque apenas a um elemento de diferenciação para a formação dos professores dos AIEF. Este aparece no parágrafo $5^{\circ}$ do art. 13, inciso IV: "[...] preponderar os tempos dedicados à constituição de conhecimento sobre os objetos de ensino e, nas demais licenciaturas, o tempo dedicado às dimensões pedagógicas não será inferior à quinta parte da carga horária total. ". (BRASIL, 2015). Denota assim uma preocupação do professor ter domínio desses conteúdos para a educação básica mas pode não romper com a lógica da docência como aquela que professa um saber apesar dessas mesmas diretrizes trazerem um conceito claro e amplo de docência. Nesta resolução o princípio da interdisciplinaridade é novamente referendado para as propostas dos cursos de formação em seu art. 7, denotando a sua permanência no histórico da legislação educacional brasileira.

\section{CONSIDERAÇÕES FINAIS}

Diante do exposto, vemos que o cenário das políticas comentadas, ainda que de forma abreviada, relacionado aos processos de regulação da construção da polivalência nos AIEF de forma geral silencia sobre algumas de suas especificidades. Os sistemas de avaliação que focalizam apenas alguns conteúdos das áreas de conhecimento e os atrelam a determinados programas de formação continuada, cujos formatos, geralmente, se apresentam com elementos contraditórios, afetam a autonomia docente e, principalmente, reduzem a polivalência, fazendo com que os professores tenham que instituir práticas de modo a se reconhecerem como professores polivalentes.

De forma geral vimos como o termo polivalência e professor polivalente, apesar de algumas diferenciações, refletem concepções de homem, sociedade e as relações socioeconômicas de forma similar nos dois momentos históricos em destaque neste texto. Assim, a noção de polivalência estaria associada a um sentido generalista e superficial de trato com os conteúdos curriculares denotando uma relação economicista de relação "custo-benefício" sob a justificativa de se suprir o déficit de professores para atuarem na crescente população escolar com ensino obrigatório estendido no período para oito anos durante o governo militar. Já a noção de professor polivalente seria associada à visão de que este seria um profissional que transita por diferentes áreas de conhecimentos articulando saberes e procedimentos, porém, com um sentido de multifuncional. Por outro lado, a noção 
de polivalência após as reformas dos anos 90 referenda a lógica das competências tanto como conteúdo formativo profissional como modo de construção do conhecimento por parte dos sujeitos.

De forma geral vemos que a elevação da formação inicial dos professores dos AIEF em nível superior constituiu no período analisado um aspecto importante no processo de profissionalização docente para essa etapa da educação escolar.

Vimos que o termo professor polivalente apareceu mais nos documentos do início dos 1990 e inferimos que por fazer referencia à condição de se ter um único professor por turma poderíamos associá-lo à noção de trabalhador polivalente ressignificada pela restruturação produtiva do capital no final dos anos 1980 e acentuada nas reformas de estado dos anos 1990.

Percebemos ainda que a lógica das habilitações polivalentes já existente desde os anos 1970 não foi de um todo retirada do cenário educacional no período correspondente a nossa pesquisa justamente por que este refletia o processo de expansão do ensino fundamental e, consequentemente, a necessidade de formar professores para atuar nas classes dessa etapa de ensino.

A análise dos documentos identificou uma noção de conhecimento baseada numa perspectiva de interdisciplinaridade um tanto frágil quando esta é transporta do contexto epistemológico para o contexto educacional e pedagógico o que fragiliza também, uma compreensão apolítica de competências nos processos de profissionalização docente reforçando uma lógica de responsabilização. A própria perspectiva interdisciplinar que seria um princípio de formação para a constituição da polivalência não tem uma sustentação sólida nas discussões das políticas, configurando-se num discurso muito genérico.

Por outro lado, a indicação do termo multidisciplinar, além de ser o termo que mais apareceu em toda a análise efetivada principalmente no período pós-reformas dos anos 1990 , apresentou um sentido quantitativo para a atuação docente nos anos iniciais e foi tratada de forma similar a outros cursos que formam professores para atuar nas outras etapas de ensino e assim não se aprofundou a especificidade da polivalência ou seja, um único professor ministrando diferentes áreas de conhecimentos. Destaca-se ainda que a discussão sobre professor multidisciplinar identificada nos documentos estudados problematiza a diferenciação e o distanciamento entre formação e atuação docente que tem perdurado na história da educação brasileira inclusive em relação ao discurso sobre as limitações entre os cursos que formam os professores dos anos iniciais e aqueles que formam professores para atuar em uma área de conhecimento específica.

\section{REFERÊNCIAS}

ALMEIDA, Edson Pacheco; PEREIRA, Rosângela Saldanha. Críticas à teoria do capital humano (uma contribuição à análise de políticas públicas em educação). Revista da UFMT. Disponível em: <http://www.ufmt.br/revista/arquivo/rev15/AlmeidaPereira.html>. Acesso em: 10 mar. 2012. 
BATISTA NETO, José. Formação de professores no contexto das reformas educacionais e do Estado. In: BATISTA NETO, José; SANTIAGO, Eliete. (Org.). Formação de professores e prática pedagógica. Recife: Massangana, 2006, p. 53-72.

BRASIL, CFE. Parecer n. 251/62. Documenta, n. 11, 1962.

BRASIL, CFE. Parecer n. 252/69. Documenta, n. 100, 1969.

BRASIL, CFE. Parecer n. 540/77. Documenta, n.195, 1977.

BRASIL, CFE. Parecer n. 853/71. Documenta, n. 100, 1969.

BRASIL, CFE. Parecer n. 867/72. Documenta, n. 140, 1972.

BRASIL. Decreto n 3.276, de 6/12/1999. Dispõe sobre a formação em nível superior de professores para atuar na educação básica, e dá outras providências. Diário Oficial da União. Brasília: Gráfica do Senado, 7 dez. 1999a.

BRASIL. Decreto $n^{\circ} 45.348$, de 27/10/2000. Regulamenta a Evolução Funcional, pela via acadêmica, dos integrantes do Quadro do Magistério, prevista no artigo 20 da Lei Complementar no 836, Brasília, 1997.

BRASIL. Estudo exploratório sobre o professor brasileiro - Com base nos resultados do Censo Escolar da Educação Básica 2007. Ministério da Educação - Instituto Nacional de Estudos e Pesquisas Educacionais Anísio Teixeira (Inep), Brasília, 2009.

BRASIL. Lei 5692/ 71 Reforma do Ensino de $1^{\circ}$ e $2^{\circ}$ graus. Brasília, 1971.

BRASIL. Parecer CNE/CEB No 2/2008. Solicitação de Parecer sobre formação e atuação de docentes na organização pedagógica do Ensino Fundamental, considerando a lógica dos ciclos de formação humana. Brasília, 2008a.

BRASIL. Parecer CNE/CEB No 4/2008 de 20/2/2008. Orientação sobre os três anos iniciais do Ensino Fundamental de nove anos. Brasília, 2008b.

BRASIL. Parecer CNE/CEB No 16/99. Diretrizes Curriculares Nacionais para a Educação Profissional de Nível Técnico, Brasília, 1999c.

BRASIL, Parecer CNE/CP Nº 9/2001. Parecer Diretrizes Curriculares Nacionais para a Formação de Professores da Educação Básica, em nível superior, curso de licenciatura, de graduação plena. Brasília, 2001.

BRASIL. Parecer CNE/CP N ${ }^{\circ}$ 10/2000 9/5/2000. Proposta de revisão do Decreto Federal no 3.276/99. Brasília, 2000.

BRASIL. Parecer CNE N ${ }^{\circ}$ 5/97 CEB 7/5/97. Proposta de Regulamentação da Lei no 9.394/96. Brasília, 1997. 
BRASIL. Parecer CNE N ${ }^{\circ}$ 11/2000 CEB 10/5/2000. Diretrizes Curriculares Nacionais para a Educação de Jovens e Adultos, Brasília, 2000.

BRASIL. Parecer CNE N 970/99 CES 9/11/99. Curso Normal Superior e da Habilitação para Magistério em Educação Infantil e Séries Iniciais do Ensino Fundamental nos Cursos de Pedagogia. Brasília, 1999b.

BRASIL. Referenciais Nacionais para a formação de professores da Educação Básica, Brasília, 2002.

BRASIL. Referenciais Nacionais para a formação de professores polivalente. Versão preliminar, Secretaria de Ensino Fundamental, Brasília, 1998.

BRASIL, Resolução CEB/CNE nº 07/2010. Fixa Diretrizes Curriculares Nacionais para o Ensino Fundamental de 9 (nove) anos. Brasília, 2010.

BRASIL. Resolução CNE 01/2006. Institui Diretrizes Curriculares Nacionais para o Curso de Graduação em Pedagogia, licenciatura, Brasília, 2006.

BRASIL. Resolução CNE/CP 01/2002. Institui Diretrizes Curriculares Nacionais para a formação de professores da Educação Básica, Brasília 2002.

BRASIL. Resolução CNE/CP N ${ }^{\circ} 1 / 1999$. Dispõe sobre os Institutos Superiores de Educação, considerados os artigos 62 e 63 da Lei no 9.394/96 e o artigo 9o, § 2o, alíneas "c" e "h" da Lei no 4.024/61, com a redação dada pela Lei no 9.131/95.

BRASIL. Resolução CNE/CP N 02/2015. Define as Diretrizes Curriculares Nacionais para a formação inicial em nível superior (cursos de licenciatura, cursos de formação pedagógica para graduados e cursos de segunda licenciatura) e para a formação continuada. Brasília, 2015.

BRZEZINSKI, Iria. Políticas contemporâneas de formação de professores para os anos iniciais do ensino fundamental. Educação \& Sociedade, Campinas, v. 29, n. 105, p. 1139 1166, set./dez. 2008.

CASTELLANI FILHO, Lino. Diretrizes gerais para o ensino de $2^{\mathbf{0}}$ grau - Núcleo comum - Educação Física. Brasília: SESG/MEC - PUC/SP, 1988.

DIAS, Rosanne Evangelista. Ciclo de políticas curriculares na formação de professores no Brasil (1996-2006). 2009. Tese (Doutorado em Educação) - Universidade Estadual do Rio de Janeiro, Rio de Janeiro, 2009.

FARIA FILHO, Luciano Mendes de. A legislação escolar como fonte para a História da Educação: uma tentativa de interpretação. In: (Org.). Educação, modernidade e civilização: fontes e perspectivas de análises para a história da educação oitocentista. Belo Horizonte: Autêntica, 1998. p. 89-125. 
FARIAS, Itamar Mazza. Diferenças entre polivalência e politecnia: implicações para a formação sobre o trabalho no processo educativo. Educação Filosofia, Uberlândia, v. 13, n. 23, p. 11-19, jan./jun. 1998.

GATTI, Bernadete Angelina; NUNES, Marian Muniz Rossa. Formação de professores para o ensino fundamental: instituições formadoras e seus currículos. Relatório final: Pedagogia. São Paulo: Fundação Carlos Chagas, 2008.

LIMA, Vanda Moreira Machado. Formação do professor polivalente e os saberes docentes: um estudo a partir de escolas públicas. 2007. Tese (Doutorado em Educação) Universidade de São Paulo, São Paulo, 2007.

MIMESSE, Eliane. O ensino profissional obrigatório de $2^{\circ}$ grau nas décadas de 70 e 80 e as aulas dos professores de história. Revista HISTEDBR On-line. Campinas, n. 26, p. 105-113, jun. 2007.

OLIVEIRA, Dalila Andrade. A Reestruturação do Trabalho Docente: Precarização e Flexibilização. Educação \&. Sociedade, Campinas, v. 25, n. 89, p. 1127-1144, set./dez. 2004.

PENNA, Maura. Música(s) e seu Ensino. Porto Alegre: Sulina, 2010.

RAMOS, Marise Nogueira. A noção de competências como ordenadora das relações educativas. In: Paulo: Cortez, 2001. A pedagogia das competências: autonomia ou adaptação? São

SANTOMÉ, Jurjo Torres. Globalização e interdisciplinaridade: o currículo integrado. Porto Alegre: Artes Médicas, 1998.

SARMENTO, Manuel Jacinto. Profissionalidade. Porto, Portugal: Porto, 1994.

SAVIANI, Dermeval. Sobre a concepção de politecnia. Rio de Janeiro: EPSJV/ Fiocruz, 1989.

YOUNG, Michael. Para que servem as escolas? Educação \& Sociedade. Campinas, v. 28, n. 101, p. 1287-1302, set./dez. 2007.

Notas

\footnotetext{
${ }^{1}$ Texto adaptado de outros dois textos publicados no Anais Eletrônico do IX SEMINÁRIO NACIONAL DE ESTUDOS E PESQUISAS “HISTÓRIA, SOCIEDADE E EDUCAÇÃO NO BRASIL”, João Pessoa-2012; e nos Anais da XI Jornada Nacional do Histedbr / Organizadores Paulo José Orso [et al] Cascavel, PR, 2013; respectivamente.

2 Professora do Departamento de Planejamento e Administração e do Programa de Pós-graduação em Educação da Universidade de Brasília.

${ }^{3}$ Pedagoga, Mestranda do Programa de Pós-graduação em Educação da Universidade de Brasília.
} 
${ }^{4}$ Professora do Departamento de Planejamento e Administração e do Programa de Pós-graduação em Educação da Universidade de Brasília.

${ }^{5}$ Para um maior aprofundamento da diferenciação entre "polivalência" e "politecnia", ver Saviani (1989) e Farias (1998).

Submetido em: 30/04/2016

Aprovado em: 10/09/2017 